\title{
DESAFIOS METODOLÓGICOS AO ESTUDO DE COMUNIDADES
} RIBEIRINHAS AMAZÔNICAS

METHODOLOGICAL CHALLENGES TO THE STUDY OF AMAZONIAN RIVERINE COMMUNITIES

\author{
Marcelo Gustavo Aguilar Calegare e Maria Inês Gasparetto Higuchi \\ Instituto Nacional de Pesquisas da Amazônia, Manaus/AM, Brasil
}

Sylvia Souza Forsberg

Universidade Federal do Amazonas, Manaus/AM, Brasil

\begin{abstract}
RESUMO
Neste artigo temos por objetivo tecer algumas considerações metodológicas necessárias aos estudos e pesquisas de campo, realizados em comunidades ribeirinhas amazônicas, a partir da Psicologia Social. Fruto de nosso contato e experiência com povos e comunidades tradicionais desta região do país, este estudo enfatiza quais as condições mínimas para que uma pesquisa nessas localidades seja possível. Também argumentamos a respeito do trabalho de campo, que exige uma atitude científica de reconhecimento da não neutralidade e do compromisso ético e político do ato de pesquisar. Abordamos ainda algumas diretrizes mais específicas e importantes para que o psicólogo social possa guiar-se em pesquisas com comunidades ribeirinhas amazônicas. Por fim, trazemos algumas sugestões de técnicas e instrumentos pertinentes às investigações realizadas nessas localidades.
\end{abstract}

Palavras-chave: comunidades ribeirinhas amazônicas; metodologia; psicologia social.

\begin{abstract}
The aim of this article is to bring some methodological considerations necessary to studies and field researches conducted in Amazonian riverine communities, from Social Psychology. As a result of our contact and experience with indigenous communities of this region of the country, we intend to emphasize what are the minimum conditions that make possible searches in these places. We argue about the field research, which requires a scientific attitude of recognition of the non-neutrality and of the ethical and political commitment of the act of researching. We discuss also about some important and specific guidelines, by which the social psychologist may conduce a research in Amazonian riverine communities. Finally, we present some suggestions for techniques and instruments relevant to investigations in these locations.
\end{abstract}

Keywords: Amazonian riverine communities; methodology; social psychology.

Se por um lado a biodiversidade da Amazônia ainda nãoé plenamente conhecida, sua sociodiversidade continua exigindo estudos que compreendam como é a vida dos distintos grupos sociais que habitam a região de forma holística. No entanto, realizar pesquisas com populações que vivem no interior da Amazônia é uma tarefa que exige do pesquisador um desprendimento incomum. Por se tratar de uma região de dimensões continentais, torna-se ardiloso empreender investigações em localidades distantes dos centros urbanos. Além das dificuldades de acesso e a quase impossibilidade de comunicação, a própria natureza amazônica exige uma série de cuidados, que os pesquisadores devem atentar para não colocarem a saúde e a vida em risco. As distâncias extensas, as intempéries ambientais e subsequentes custeios estratosféricos de deslocamento e acomodação são elementos que exigem motivação e modo de agir para além do habitual fazer científico.

Além desses aspectos, o pesquisador está frente a frente com uma cultura bastante peculiar, cujos códigos podem não ser facilmente apreensíveis e compreensíveis. Embrenhar-se nessa realidade é enfrentar um longo caminho antes de propriamente iniciar a pesquisa seguindo os procedimentos metodológicos específicos. Essas externalidades, sempre presentes nos estudos, são raramente 
consideradas como aspectos metodológicos. Seriam meras externalidades se não estivessem inseridas no fazer científico e o pesquisador não se considerasse um agente de produção desses conhecimentos, juntamente com o seu informante naquele contexto.

Já nos relatos de Wallace (1853), a respeito de suas viagens ao rio Negro e Solimões, encontramos situações semelhantes às que ainda hoje temos. Dificuldades de navegação pelos rios, principalmente quando secam, a precariedade das casas oferecidas para abrigo, os insetos como piuns e formigas de fogo que atacam os desprevenidos, tudo isso contrastando com as pessoas sempre muito agradáveis e cordiais. Ademais, como relatou Wallace (1853) e ainda é válido até o momento, não é prudente empreender uma viagem por vários meses, por tão remotos lugares, sem estar bem suprido com uma considerável quantidade de material para subsistência e também para fazer permuta com os moradores locais.

Diante de tais colocações, neste artigo temos por objetivo tecer algumas considerações metodológicas necessárias à realização de estudos e pesquisas de campo em comunidades ribeirinhas amazônicas, a partir da Psicologia Social. Fruto de nosso contato e experiência com povos e comunidades tradicionais desta região do país, objetivamos trazer algumas discussões que consideramos parte implícita de um proceder metodológico, mas que deve ser explicitado.

Partindo da Psicologia Social, mais especificamente sob o viés das abordagens da Psicologia Comunitária e da Psicologia Política, nos propomos a enfatizar quais as condições mínimas para que uma pesquisa nessas comunidades seja possível. Também argumentamos a respeito do trabalho de campo de modo geral, que exige uma atitude científica que reconheça a não neutralidade e, por outro lado, tenha como norte o compromisso ético e político do ato de pesquisar. Como lembra Japiassu (1975), assumir a ciência como não neutra implica ao pesquisador repensar e ressituar suas práticas e seus sujeitos. Abordamos ainda algumas diretrizes mais específicas e importantes para que o psicólogo social possa guiar-se em pesquisas com comunidades ribeirinhas amazônicas. Por fim, trazemos algumas sugestões de técnicas e instrumentos de pesquisa pertinentes às pesquisas realizadas nessas localidades.

\section{A pesquisa em função das distâncias, logística e verbas}

Há pesquisas que se iniciam em função de uma abordagem teórica. Como toda teoria é um instrumento para leitura da realidade, o pesquisador se utiliza de uma das várias lentes disponíveis na ciência moderna para compreender certos fenômenos que o inquietam. Por exemplo, podemos dizer que a Psicologia Política é uma subdisciplina da Psicologia Social orientada ao estudo dos fenômenos políticos (Montero, 2009). A partir dessa referência teórica, um pesquisador pode querer estudar a participação política da população residente na gestão de uma unidade de conservação (UC), buscando compreender os motivos que levam essas pessoas ao maior ou menor envolvimento nas tomadas de decisão e no uso dos recursos naturais e/ou conservação destes.

Outras pesquisas se iniciam em função de uma especificidade das teorias, isto é, um conceito que demonstre adequação para fazer boas leituras da realidade. Dentro do arcabouço teórico da Psicologia Política encontramos o conceito de identidade coletiva, por exemplo. Este nos permite compreender o processo pelo qual determinados sujeitos coletivos constroem o reconhecimento e sentimento de pertencimento a um determinado grupo social, configurando-lhes possibilidades e limites de ações coletivas (Prado, 2001). Por meio desse conceito, um projeto de pesquisa pode ser elaborado com o objetivo de estudar o processo pelo qual os indígenas da etnia Kokama vêm resgatando suas identidades, como estratégia de luta política por direito ao território e/ou acesso a bens e serviços sociais (Calegare, 2010a).

Existem pesquisas que são delineadas em função de um método de investigação. Os adeptos da pesquisaação procuram elaborar suas estratégias e objetivos de pesquisa de maneira a envolver os participantes na construção participativa de um projeto coletivo, com vistas à transformação da realidade vivida por estes (Thiollent, 1988). Por meio dessa modalidade metodológica, o pesquisador pode descobrir que uma determinada comunidade ribeirinha possui vocação ao manejo de madeira caída e, por ações conjuntas, elabora-se um plano de produção de pequenos objetos de madeira.

Podemos elencar muitos outros fatores modeladores de pesquisas, como por exemplo, um problema vivenciado por determinado segmento social, que necessita de investigações para encontrarem soluções adequadas. Ou um fenômeno intrigante, que instiga os pesquisadores a desvendar por que, como, quando e onde este acontece.

No interior da Amazônia a disponibilidade de verba e o apoio logístico também devem ser vistos como fatores críticos na estruturação de um programa de pesquisa, já que as pesquisas só se iniciam caso haja 
verba para subsidiar o oneroso transporte necessário para percorrer as longas distâncias da região. Isso significa que qualquer que seja o viés teórico, os conceitos, os métodos ou outros fatores importantes à condução de uma investigação, o que determina a factibilidade do trabalho científico nesta região do país são as distâncias (em relação aos centros urbanos) e as condições logísticas para os deslocamentos.

A Amazônia ocupa $60 \%$ do território nacional e, por conta dessas dimensões continentais, chegar até determinadas localidades exige meios de transportes específicos, que nem sempre são muito econômicos. As distâncias percorridas levam mais do que dias para serem transpostas e, dependendo da localidade e sazonalidade, as condições de acesso são precárias e difíceis de serem superadas. Em determinadas épocas, o curso do rio que leva a uma localidade está seco, exigindo dos pesquisadores o carregamento da canoa para depois retomá-la mais adiante e continuar seu curso fluvial.

Isso nos mostra que realizar uma pesquisa em comunidades ribeirinhas só acontece caso haja financiamento, apoio logístico local disponibilizado por órgãos governamentais e/ou não governamentais, apoio dos líderes comunitários, moradores e, sobretudo, do desprendimento e motivação do pesquisador. Uma vez de posse das verbas disponíveis, o desenho metodológico da pesquisa ocorrerá em função da distância e da logística necessária para os deslocamentos. A investigação propriamente dita, que envolve ponderar número de dias em campo, objetivos a serem cumpridos, tipo de método e de técnicas empregados, ocorre de forma bastante associada com tais peculiaridades descritas.

Dadas tais condições de acesso às comunidades ribeirinhas amazônicas, elaborar um projeto de pesquisa exige, necessariamente, considerar a distância, tempo e formas (terrestre ou/ou fluvial) de deslocamento e os respectivos custos para se chegar até o local de destino. Essas particularidades, de modo geral, são mal compreendidas pelas agências financiadoras, pois os custos com transporte tornamse elevados e acabam por representarem grande parte do orçamento da pesquisa. Em muitos casos o acesso à alimentação é inexistente, tendo que ser levada na expedição, considerando ainda compartilhar com os membros das comunidades, pois na cultura local está implícita tal partilha. Em muitos casos o pesquisador deve considerar um montante de combustível para efeitos de troca. É comum ele ser abordado para fornecer diesel para alguma emergência (levar uma pessoa doente até o atendimento mais próximo), usar no gerador de energia, trocar por alimento ou até usar como pagamento em caso de necessitar de guia de deslocamento pelos rios ou comunidades.

Diante desse primeiro desafio metodológico, temos ainda outros dois desdobramentos a serem considerados:

1. Projetos individuais raramente possuem recursos disponíveis suficientes. É salutar que estes façam parte de um programa de pesquisa mais abrangente e multidisciplinar, para que seja possível compartilhar verbas para as despesas com as viagens e segurança de trabalho. No estado do Amazonas, nas universidades ou nos institutos de pesquisa federais, são muito comuns que as expedições, também chamadas de excursão de pesquisa, sejam otimizadas com equipes de vários focos disciplinares, que combinam épocas e períodos específicos para contornar as dificuldades de acesso, custos e segurança. Isso significa que as idas a campo são realizadas, em geral, em equipes multidisciplinares que, no exercício da práxis de coleta, acabam por se constituírem em espaços pródigos para proposição de futuras pesquisas interdisciplinares. Essas proposições, no entanto, não nascem como uma estratégia objetiva diante da dificuldade, mas na discussão da realidade encontrada e no entendimento das complexidades de campo que acenam para estudos mais holísticos da problemática com que o pesquisador se depara. Desse modo, os pesquisadores do Norte do Brasil estão sendo colocados diante da necessidade, cada vez mais premente, de introduzir as questões da interdisciplinaridade, como a entende Fazenda (2007), na realização de pesquisas. De acordo com a autora, a ação é o ponto de partida e convergência entre o pensar e o fazer interdisciplinar.

Diante de tais colocações, entendemos que não é uma ou outra disciplina que permitirá plenos conhecimentos sobre a vida nas comunidades ribeirinhas amazônicas. Pelo contrário, devemos considerar que as comunidades ribeirinhas são o campo de estudos interdisciplinares, em analogia com o que sugere Diegues (2004) para o mar.

2. Especialmente no estado do Amazonas, onde há pouquíssimas rodovias e o transporte é prioritariamente realizado por via fluvial, as viagens a campo devem ser cuidadosamente planejadas, com objetivos claros, métodos plausíveis e instrumentos adequados. É especialmente importante, neste contexto, considerar as variações dos níveis da água dos rios vinculados ao ciclo das chuvas. $\mathrm{O}$ acesso às comunidades ribeirinhas é sempre melhor no período de cheia e dificultado no período de seca. Desse modo, a escolha do número e período de visitas e do tempo de permanência deve levar em consideração aspectos 
centrais da população estudada, para que, adequandose às condições logísticas, seja factível realizar a investigação.

Outra realidade são as chuvas que, na época de dezembro a abril (período chamado de inverno), a precipitação é bastante elevada, tornando o deslocamento lento e perigoso. Nessa época, com o calor e a alta umidade do ar, é um período propício para fungos, trazendo problemas de insalubridade. $\mathrm{Da}$ mesma forma, existem áreas de proliferação acentuada de insetos que chegam a impedir a realização plena do trabalho para o pesquisador que não está habituado com tais adversidades, ou que não tenha se precavido para essa situação.

Portrás desses fatoreshátambéma disponibilidade dos pesquisadores, que devem abandonar suas rotinas, afazeres e obrigações acadêmicas e pessoais para poder realizar as viagens a campo - que fascina e instiga a todos que vêm realizar pesquisas nesta região.

\section{O trabalho de campo: compromisso ético e político da construção participativa do conhecimento}

O trabalho de campo, de acordo Minayo (2007), "permite a aproximação do pesquisador da realidade sobre o qual formulou uma pergunta, mas também estabelece uma interação com os 'atores' que conformam a realidade e, assim, constrói um conhecimento empírico importantíssimo" (p.61). A autora define "campo, na pesquisa qualitativa, como o recorte espacial que diz respeito à abrangência, em termos empíricos, do recorte teórico correspondente ao objeto da investigação" (p.62).

Como já pontuado anteriormente, as teorias são instrumentos de leitura da realidade - e não a realidade propriamente dita, como muitas vezes alguns pesquisadores podem confundir. Em nosso caso, estamos tratando da realidade da vida das pessoas que vivem em comunidades ribeirinhas amazônicas. Como esse universo amostral é extenso demais, em geral fazem-se recortes do que se pretende estudar, conforme explica Minayo. Por exemplo, Silva (2008) estudou as formas de ajuda mútua e trabalho coletivo, Oliveira (2008) focou na organização sociopolítica dos pescadores artesanais, Alencar (2005) examinou as políticas públicas voltadas às comunidades rurais, Calegare (2010a) estudou as redes comunitárias e identidades coletivas, entre outros muitos estudos que poderíamos citar. Em todos os casos, os pesquisadores realizaram o trabalho de campo de acordo com o viés dado às suas pesquisas.
Para que as atividades de campo sejam possíveis, o pesquisador deve estar munido não apenas de abordagens teóricas e instrumentos de pesquisa, mas também deve carregar consigo um princípio fundamental para as investigações nesta região: o respeito à diversidade social e às práticas cotidianas da comunidade. Tais elementos não são inéditos, mas constituem tanto aspectos éticos quanto informações socioculturais e contextuais para compreender a dinâmica psicossocial daquelas pessoas. Isso remete a uma antiga discussão sobre o contato entre pesquisador/ pesquisado, que permeia o cunho participativo de pesquisas fora dos laboratórios.

Para Schimdt (2006), no início da pesquisa etnográfica clássica pretendia-se uma objetividade das informações coletadas e se cercava metodologicamente de recursos para criá-la, reforçando o caráter positivista que cindia sujeito/objeto. No entanto, ao tratar com indivíduos/grupos, passou-se a questionar que esses objetos não eram passivos, ou seja, o outro era sujeito ativo na produção do conhecimento. Portanto, a problemática da relação com o outro está posta desde o princípio numa pesquisa em que o pesquisador é participante do cotidiano do pesquisado, o que exige repensar a maneira como o conhecimento é construído nessas circunstâncias.

$\mathrm{Na}$ esteira de Brandão (1999), a observação participante (um instrumento etnográfico) se torna pesquisa participante por influência marxista, na medida em que o pesquisador compreende o outro não apenas pela "convivência", mas também pelo "compromisso" político em participar de sua história. Nesse sentido, a pesquisa de cunho participante requer a inserção do pesquisador num campo de investigação formado pela vida social e cultural do outro, mas ao mesmo tempo considera-o como coprodutor do conhecimento. Isso porque é só a partir da colaboração deste outro, seja na qualidade de informante ou interlocutor, que essa produção é possível.

De acordo com a perspectiva de Brandão, estamos diante de um panorama metodológico em que $o$ ato de pesquisar, em hipótese alguma, configura neutralidade por parte do pesquisador. Ao fazer contato com os pesquisados, ao estabelecer os termos e acordos da pesquisa, ao pisar no campo, ao conversar com as pessoas, ao criar expectativas e fantasias pela sua presença, ao interagir com gente de todas as idades, gênero e posição social, a pesquisa torna-se parcial.

Seguindo a compreensão de Schmidt (2006), o ponto central da presença do pesquisador em campo é que esta deve ser pensada a partir da relação de alteridade (altereitas - diferença, diversidade) e da capacidade autorreflexiva dos envolvidos na 
pesquisa. Elas tensionam objetividade/subjetividade e constituem pontes entre o trabalho de campo e a escrita etnográfica. Isso quer dizer que estar no lugar de vida dos interlocutores da pesquisa significa considerar as implicações éticas e políticas dessa interação.

De acordo com essa abordagem, a construção de sentido da alteridade é resultado do diálogo que se estabelece entre os interlocutores, da negociação de sentidos e do intercâmbio entre saberes. Por esse motivo é que afirmamos que a presença do pesquisador no local de pesquisa configura sempre uma situação de participação: mesmo que ele não se engaje diretamente nas lutas dos pesquisados, sua atitude de pesquisa implica, necessariamente, no envolvimento com estes. Portanto, sempre se está implicado eticamente com o outro, restando-lhe dar o devido valor do outro à construção do conhecimento. Deve-se falar em construção participativa do conhecimento e ter isso como compromisso ético em todas as etapas da pesquisa (antes, durante e depois de sua realização).

Tal perspectiva é corroborada por Guareschi (1996) ao descrever que as relações nunca se predicam de um só elemento, pois elas sempre implicam em dois. Por essa razão, deve-se considerar a interação que se estabelece entre os envolvidos segundo sua dimensão ética. Nesse sentido, entendemos o outro como "parceiro na construção de interpretações da cultura e para empreender a reflexão sobre as relações de poder entre pesquisador e pesquisados, bem como sobre o sentido ou a utilidade da pesquisa etnográfica um para o outro" (Schmidt, 2006, p.27). Por tais colocações, o próprio encontro/relação é entendido como fonte de significação e de conhecimentos. O outro não é apenas informante, mas sim interlocutor. Em outras palavras, a relação entre pesquisador/ pesquisado e o conhecimento gerado não podem ser compartimentalizados, mas devem ser tratados como um único processo e produto.

De acordo com o exposto sobre o compromisso ético, entende-se que o engajamento político do pesquisador inicia-se a partir do momento em que delineia a pesquisa e na maneira como concebe a construção do conhecimento, e não apenas na participação direta nas lutas políticas dos coletivos. Ao considerar a relação de alteridade como uma das chaves da leitura etnográfica, coloca-se o pesquisado em primeiro plano como interlocutor da situação estudada. E, ao assim proceder, é essencial se levar em consideração a implicação política dos acordos feitos entre pesquisador/pesquisado, pois toda e qualquer informação que se venha a obter é fruto do consentimento, de ambas as partes, em tocar a pesquisa adiante. Isso indica que os procedimentos éticos não devem se restringir apenas à informação do pesquisado sobre os objetivos, métodos e utilização de dados da pesquisa em atividades posteriores às idas a campo. A ética e o compromisso político do pesquisador estão pautados também em confirmar as informações junto aos pesquisados, na devolutiva final e no uso posterior das informações obtidas.

Se o outro é colocado na posição de coautor do conhecimento construído, este contato no trabalho de campo é o que Oliveira (2006) nomeia como "estar lá”, complementando a dupla situação etnográfica pelo par "estar aqui". Este último se caracteriza como o momento em que o pesquisador produz um texto que deriva de sua experiência em campo, buscando compreender seu lugar diante do outro, num movimento de autorreflexão que se acentua no gabinete. A produção do texto é mais do que a retomada de registros. Trata-se da recuperação da cena em que se estabeleceu uma relação de confiança e, por esse motivo, os escritos atualizam o compromisso ético e político assumido com os interlocutores, implícita ou explicitamente.

Diante de tais colocações, vemos que o desafio metodológico ao estudo das comunidades ribeirinhas amazônicas não se restringe apenas a ir até as comunidades, isto é, realizar o trabalho de campo. É preciso colocar em questão o contato estabelecido entre pesquisador/pesquisado, para ponderar como se constrói o conhecimento em uma pesquisa de cunho participante.

\section{O psicólogo social em campo}

Em nossa busca por uma atuação que configurasse o trabalho do psicólogo social em campo nas comunidades ribeirinhas amazônicas, lançamos mão das elaborações técnico-teóricas oriundas da Psicologia Comunitária. Já existe produção latinoamericana (e brasileira) relevante de atuação de psicólogos sociais em comunidades - apesar de em geral serem estas urbanas. A literatura na área e as experiências comunitárias têm demonstrado que existem estratégias interessantes que podem ser adaptadas ao contexto amazônico. Por outro lado, a compreensão de alguns fenômenos psicossociais da vida comunitária na Amazônia é facilitada por meio da produção teórica da Psicologia Política, especialmente no que se refere aos fenômenos psicopolíticos (Freitas, 2001).

Vejamos então quais são as orientações para os psicólogos sociais desenvolverem suas pesquisas em comunidades ribeirinhas amazônicas, que aliem 
produção de conhecimento e ações ligadas à formação de consciência crítica, processos de participação e melhoria da qualidade de vida da população local.

Para Freitas (1999), o trabalho em comunidades deve ser de caráter ativo e participativo, no sentido de que o psicólogo social é convocado a fazer parte das atividades do cotidiano das pessoas, deixando de lado as pretensões de neutralidade típica de uma visão tradicional de ciência. Essa atitude deve pautar-se na atuação centrada no compromisso ético e político com os atores sociais, em que se preza pelo desenvolvimento comunitário. Isso acontece por meio do acompanhamento daquilo que a própria comunidade decide e encaminha como alternativas para melhoria da qualidade de vida. De acordo com a autora, a postura do psicólogo (social) em um trabalho comunitário tem como características principais: (a) ser um trabalho de cunho multidisciplinar; (b) ser orientado pelas necessidades e demandas coletivas; (c) lidar prioritariamente com grupos e, portanto, levar em conta os processos grupais; (d) ter conhecimento contínuo e atualizado sobre dinâmica comunitária, que imprime novas diretrizes ao trabalho; (e) admitir mudanças constantes nas estratégias, objetivos, problemas, alternativas, etc.; (f) questionar a todo o momento a importância e viabilidade do trabalho; (g) o tempo previsto de ação deve ser avaliado junto à comunidade.

Martín-Baró (1998) ilustra que o fazer científico deve estar comprometido com a sua própria realidade histórica e com os problemas e anseios de seu povo. Isso significa que o psicólogo social deve buscar formular suas estratégias não apenas em pressupostos, métodos e teorias prontas para fortalecer sua disciplina científica, mas estar comprometido com uma atuação condizente com as necessidades daqueles que ele busca auxiliar. Ao tratar das comunidades ribeirinhas amazônicas, essa referida atuação estará ligada, muito provavelmente, às questões relacionadas ao uso/manejo de recursos naturais, posse/conflito por territórios, acesso a bens e serviços sociais, resgate de conhecimentos tradicionais, valorização da cultura local, transformações identitárias, entre outras questões regionais amazônicas.

A atuação no contexto amazônico implica fazer uma boa leitura de conjuntura, como recomenda Martín-Baró (1998). Do complexo cenário amazônico atual, podemos elencar alguns elementos do pano de fundo que compõe o momento vivido pelas populações locais: (a) o Desenvolvimento Sustentável e o jogo de interferências nacionais/ internacionais que modelam programas e projetos destinados à sustentabilidade da Amazônia, especialmente aqueles ligados ao uso sustentável de recursos naturais; (b) a conservação da biodiversidade amazônica, que aos poucos vem sendo conjugada com a sociodiversidade. Dentro desse panorama é que surgem as discussões sobre UC de uso sustentável e a Prestação de Serviços Ambientais pelas comunidades locais; (c) a proteção dos conhecimentos tradicionais, o combate à biopirataria, a discussão sobre propriedade intelectual e de patentes, a defesa de recursos genéticos e biodiversidades da floresta amazônica; (d) lutas por territórios, que garantem acesso e uso aos recursos naturais por povos e comunidades tradicionais e que têm gerado conflitos armados em muitas regiões amazônicas.

O compromisso de atuação do psicólogo social deve ser condizente com a atitude de uma pesquisa que recusa a neutralidade e os laboratórios, e é engajada e estimulada em razão da busca de soluções para os cenários em que ela ocorre. Nesse sentido, Campos (1996) descreve que os trabalhos comunitários devem partir de um levantamento das necessidades e carências vividas pelo grupo, especialmente aquelas referentes ao acesso a direitos e ao cumprimento de deveres inerentes ao exercício pleno da cidadania.

Para Campos (1996), as intervenções são realizadas por métodos e processos de conscientização, em que as pessoas progressivamente: (a) assumem o papel de sujeito ativo e participativo de sua história; (b) conscientizam-se dos determinantes sociopolíticos das situações vividas; (c) buscam soluções aos problemas encontrados. Esse agir é norteado pelo incentivo à busca da consciência crítica, da ética da solidariedade e de práticas cooperativas e/ou autogestionárias, a partir da análise concreta dos problemas cotidianos de uma comunidade.

Dentre as colocações da autora, existem três perspectivas subjacentes ao desenvolvimento dos trabalhos comunitários: (a) teórica - diz respeito à interação entre sujeitos na construção participativa do conhecimento; (b) metodológica - que envolve, necessariamente, a adoção de pesquisas de cunho participante e (c) de valores - questiona-se a ciência como atividade não valorativa e assume-se ativamente o compromisso ético e político.

Já abordamos anteriormente esses três aspectos levantados por Campos (2006). No entanto, temos algumas considerações em relação ao norte das ações do psicólogo social, especificamente nas comunidades ribeirinhas amazônicas. Apesar de desejosos de despertar consciência crítica, nossa experiência com trabalhos na Amazônia nos mostra que é preciso primeiro respeitar o modo de vida das pessoas, antes de julgar a necessidade de lhes despertar algo que, talvez, já o tenham há tempos. Trata-se de uma 
atitude cautelosa e respeitosa para entender como esses grupos lidam com suas dificuldades e anseiam por determinados objetivos, ao invés de partir do pressuposto da carência generalizada, cegueira política ou alienação que necessitam de urgente resolução. Isso significa que devemos compreender como se manifesta a consciência crítica dessas pessoas, suas peculiaridades e o modo como elas, a partir da percepção das situações vividas, se engajam em ações coletivas.

Em relação ao estímulo ao cooperativismo e/ ou associativismo, também devemos abordar essas perspectivas com parcimônia, pois as comunidades ribeirinhas não necessariamente precisam desse tipo de estímulo. Como frisa Chaves (2001), há um mecanismo interno de organização particular às comunidades amazônicas, que deve ser entendido e respeitado. Temos visto que é mais interessante compreender como cada comunidade se organiza, segundo suas redes internas e jogos de poder, para conseguir, a partir dessas tramas, estimular as pessoas em empreendimentos coletivos inovadores.

Por fim, a ética da solidariedade é uma das características marcantes da vida nas comunidades ribeirinhas amazônicas. É extremamente comum encontrarmos regimes de trabalhos coletivos e ajuda mútua nessas localidades, como expõe Silva (2008), tal qual o mutirão e o ajuri. O primeiro se refere aos trabalhos realizados por um grupo em prol de um benefício comunitário, enquanto o segundo se destina ao benefício de uma pessoa, que convoca os amigos para auxiliá-lo em uma tarefa. Isso demonstra que se deve, primeiramente, compreender como funcionam os laços de solidariedade e, diante desse reconhecimento, utilizar-se dessa lógica comunitária para poder desenvolver projetos locais.

Como vimos, o trabalho em campo do psicólogo social em comunidades ribeirinhas amazônicas não condiz com a neutralidade científica, mas com uma atuação comprometida com a transformação das condições de vida das pessoas para melhor, segundo elas mesmas julguem como tal. Para tanto, é de suma importância estar a par das discussões que vêm permeando o contexto amazônico na atualidade, bem como pautar-se em referenciais de ação e produção de conhecimento que respeitem o modo de vida nessas comunidades.

\section{Desenho metodológico}

Argumentamos a respeito da atitude que um pesquisador deve ter para o estudo de comunidades ribeirinhas amazônicas, independente de sua formação ou viés teórico. Também expusemos diretrizes norteadoras do trabalho de campo aos psicólogos sociais que querem atuar na Amazônia. Restanos entender como proceder às pesquisas nessas localidades.

Conforme a área de especialidade do pesquisador, a tendência é a utilização de métodos e instrumentos com os quais ele tenha intimidade para chegar a seus objetivos. Os psicólogos sociais teriam instrumentos privilegiados para lograr alcançar seus objetivos de pesquisa nas comunidades ribeirinhas amazônicas?

Nossa experiência em pesquisas nessas localidades tem mostrado que os métodos e instrumentos provenientes de apenas uma disciplina são insuficientes para compreender a realidade de vida da população local. Mesmo dentro de uma grande área, como as ciências sociais, os modelos de estratégias de pesquisa não são perfeitamente encaixáveis ao universo amazônico. Isso porque estamos tratando de uma realidade complexa, que exige dos pesquisadores repensar como fazer para abordar um objeto difícil de ser captado.

Algumas abordagens clássicas de pesquisa para os cientistas sociais são as seguintes: pesquisa experimental, survey/levantamento, pesquisa histórica, análise de arquivos/documental, estudo de caso, pesquisa etnográfica/observação de participantes, pesquisa-participante, pesquisa-ação. Para fins de inteligibilidade com outros cientistas, costuma-se adotar um desses modelos, por serem previamente testados e aprovados pela comunidade científica. Cada um deles envolve a utilização de instrumentos condizentes com a maneira como se concebe o ato de pesquisar. No caso de pesquisas com as comunidades ribeirinhas amazônicas, é preciso examinar como utilizar essas metodologias, fazendo as adaptações necessárias em função das verbas, distâncias, logística, equipe, objetivos, condições locais, etc. O ponto central deve ser o fenômeno a ser investigado, buscando-se o caminho mais factível para compreendê-lo.

De um ponto de vista mais amplo das ciências sociais, dentro da qual a Psicologia Social se insere (Calegare, 2010b), Minayo (2007) destaca que os tipos de estudos privilegiados são aqueles de abordagem qualitativa. De acordo com a autora, "para fins bem práticos, dividimos o processo de trabalho científico em pesquisa qualitativa em três etapas: (1) fase exploratória; (2) trabalho de campo; (3) análise e tratamento do material empírico e documental" (p.26). A primeira refere-se à produção do projeto de pesquisa e procedimentos necessários para preparar a entrada em campo. A segunda consiste em levar 
para a prática empírica a construção teórica elaborada anteriormente. A terceira é a ordenação, classificação e análise propriamente dita dos dados, em que se busca a "lógica peculiar e interna do grupo que estamos analisando, sendo esta a construção fundamental do pesquisador" (p.27).

O esquema metodológico generalizado por Minayo nem sempre funciona da maneira como está explicado. Como vimos insistindo, a realidade amazônica não é facilmente captável e cada viagem a campo nos surpreende e exigem que reconfiguremos todo o planejamento prévio - tanto durante a pesquisa in loco como entre as viagens. Disso resulta não ser tão simples obedecer à sequência: preparação teórica, ida a campo, sistematização de dados comprovando ou refutando visões teóricas.

Temos outro desafio metodológico a ser levado em consideração: a compreensão teórica não se restringe aos momentos precedentes às idas a campo, mas é em boa parte buscada durante e após as vivências práticas. Isso vem ao encontro do que argumentamos anteriormente: a construção do conhecimento acontece na interação entre pesquisador/pesquisado. O contato com a população ribeirinha amazônica faz repensar não apenas a etapa de coleta de dados, mas os próprios modelos teóricos que nos baseamos para abordar a realidade. Examinando as teorias de Psicologia Social, nos damos conta que ainda há pouca produção que verse a respeito das comunidades ribeirinhas amazônicas. Portanto, os modelos teóricos utilizados neste universo são provenientes de outros contextos e devem ser questionados e adaptados, para que possam servir como instrumentos de leitura da Amazônia.

De um lado observamos que as teorias produzidas em contextos não amazônicos nem sempre são adequadas ao estudo dessa realidade. Por outro, temos que os próprios instrumentos de pesquisa tampouco podem ser plenamente eficazes para captar as informações necessárias a uma investigação. Por conta disso é que preferimos desenvolver pesquisas que aliam métodos quantitativos e qualitativos. Tal qual refere Minayo (2005), é interessante utilizar a triangulação de métodos para lograr captar distintos aspectos de um objeto de estudo. Nós temos preferido denominá-la de abordagem multimétodos (triangulação ou mixed methods) (Günther, Elali, \& Pinheiro, 2011) para explicitar que os temas ligados às comunidades rurais amazônicas necessitam de uma série de instrumentos para serem compreendidos em profundidade. Sommer (2003) assinala que a Psicologia - e também a Psicologia Social - deve promover habilidades nos estudantes para que estes possam saber ler e lidar com a riqueza do ambiente ao seu redor. Nesse sentido, a abordagem multimétodos poderia fornecer ao aluno esta leitura.

A eleição de quais instrumentos utilizar dependerá dos objetivos do projeto de pesquisa, do tempo disponível em campo e das condições de sua aplicabilidade nas comunidades. Abaixo elencamos alguns deles, a título de ilustração das possibilidades que acreditamos serem pertinentes aos estudos em comunidades ribeirinhas amazônicas:

1. Formulário socioeconômico. O formulário é um instrumento de coleta de dados que possui perguntas abertas e fechadas aplicadas pelo pesquisador. Diferencia-se do questionário porque este último é respondido pela própria pessoa (Appolinário, 2004). Mostra-se interessante para obter um perfil socioeconômico dos habitantes da comunidade, com dados quantitativos.

2. Entrevistas semiestruturadas. O recurso à entrevista é comum e preferencial a pesquisadores que vão a campo, segundo Minayo (2007). Do mesmo modo, a entrevista é o instrumento predileto daqueles advindos da Psicologia Social. As vantagens da entrevista são sua flexibilidade, seu contato mais próximo com os sujeitos, a possibilidade de colher atitudes gerais do interlocutor diante das perguntas e a criação de uma atmosfera de confiança que se estabelece entre os envolvidos (Bosi, 1998).

3. Grupo Focal. Para Lervolino e Pelicioni (2001), "a essência do grupo focal consiste justamente na interação entre os participantes e o pesquisador, que objetiva colher dados a partir da discussão focada em tópicos específicos e diretivos" (p.116). Igualmente às entrevistas semiestruturadas, a partir das respostas do roteiro inicial, podem-se fazer perguntas para aprofundar temas emergentes durante a entrevista.

4. Reuniões comunitárias e técnicas de abordagem grupal. O objetivo dessas reuniões é apresentar, explicar os objetivos das pesquisas, obter informações, estabelecer acordos com os moradores e lideranças comunitárias a respeito das atividades a serem desenvolvidas, bem como transmitir os resultados obtidos nas visitas anteriores. Utiliza-se técnicas de abordagem grupal para facilitar a explicação de alguns tópicos e para coleta de informações.

5. Participação nas atividades cotidianas $e$ diário de campo. É anotar em um caderno as impressões e vivências a partir da participação nos trabalhos coletivos, reuniões, eventos religiosos, pescaria, agricultura, produção de farinha, preparo de açaí, refeições, conversas com agentes do governo presentes na comunidade e fora dela, além de outros eventos e experiências vivenciadas com indivíduos 
ou com pequenos grupos. Em diversas ocasiões, as conversas informais com as famílias tornaram-se verdadeiras entrevistas coletivas, sem roteiros prévios ou formalidades de algum instrumento.

6. Mapas cognitivos com elaboração de croqui de uso social. Trata-se de um desenho da comunidade contendo informações sobre localização espacial das casas e outras construções, roças, área de lazer, entre outros dados que se julguem relevantes. Esta técnica pode ser utilizada também para coleta de relatos de lutas políticas, como aquelas por territórios e reconhecimento identitário, tal qual vem sendo desenvolvida pelo Projeto Nova Cartografia Social da Amazônia.

7. Registro fotográfico. Como ressalta Simonian (2007), o uso de imagens não é de cunho meramente ilustrativo para uma pesquisa, mas pode servir como base de dados e abrir espaço para interpretações da realidade amazônica: aspectos naturais, históricoculturais e/ou sociais. Entretanto, o uso de imagens deve obedecer aos costumes e hábitos culturais próprios da comunidade e do desejo dos indivíduos. É desnecessário dizer que a fotografia é um recorte instantâneo de uma realidade em movimento e por isso expressa esse contexto. Sendo assim, o registro é fonte de informação a ser analisada como complemento de compreensão da dinâmica socioambiental comunitária.

8. Reuniões de equipe. Este tipo de reunião se assemelha ao que, no universo discursivo da Análise Institucional, se chama de análise de implicação. Realizada apenas entre os pesquisadores, seu objetivo é problematizar os tipos de relações que se estabeleceram entre esses pesquisadores/pesquisados, compreender melhor a dinâmica comunitária e contribuir para a tomada de decisões mais precisas sobre os redirecionamentos dos próximos passos da pesquisa.

\section{Considerações finais}

Vimos que o primeiro desafio metodológico ao estudo de comunidades rurais amazônicas é conseguir obter verbas para realização das pesquisas, dispor de condições de acesso disponíveis e lidar com as intempéries ambientais. O dinheiro será empregado, principalmente, para o custeio e logística da expedição até as mais longínquas localidades. Diante desse fato, deve-se articular com cuidado os objetivos de pesquisa às condições logísticas e tempo de permanência em campo, pois só dessa maneira se conseguirá executar a investigação. A contingência amazônica vem nos mostrar que pesquisar envolve muito mais do que apenas dominar a linguagem científica: a Amazônia faz com que se explicitem as condições subjacentes de produção do conhecimento.

O trabalho de campo em comunidades ribeirinhas amazônicas é, muitas vezes, confundido com apenas um nicho de antropólogos, mas exige dos psicólogos sociais repensar a forma como constroem os conhecimentos nas visitas a essas localidades. Nesse sentido, argumentamos suficientemente que se devem considerar os participantes da pesquisa como interlocutores, pois é do contato com estas pessoas que se produzem conhecimentos.

Além de trazer algumas adaptações da atuação em comunidades oriundas da Psicologia Comunitária nos aspectos convergentes com a Psicologia Política, vimos que os psicólogos sociais devem estar a par de uma série de discussões que permeiam o contexto amazônico. Caso não esteja inteirado dessas importantes questões conjunturais, corre-se o risco de atuar de maneira alienada à realidade local e agir simplesmente por conta da uma ideologia da transformação, sem se saber a qual norte chegar. O erro de muitos pesquisadores é chegar com uma visão exterior, produzida em outro contexto, e aplicá-la impensadamente aos casos amazônicos.

Por fim, o ato de proceder à investigação propriamente dita envolve, em nosso ponto de vista, a utilização da abordagem multimétodos, que se mostra mais adequada para conseguir captar a complexa realidade socioambiental amazônica. As práticas dos grupos de pesquisa da região Norte tem demonstrado que esse tipo de abordagem produz melhores resultados investigativos, o que vem gerando renovações, inovações e rompimento de paradigmas inadequados à Amazônia.

\section{Referências}

Alencar, E. F. (2005). Políticas Públicas e (in)sustentabilidade social: o caso de comunidades de várzea no Alto Solimões, Amazonas. In D. M. Lima (Org.), Diversidade socioambiental nas várzeas dos rios Amazonas e Solimões: perspectivas para o desenvolvimento da sustentabilidade (pp. 55-99). Manaus: Ibama, ProVárzea.

Appolinário, F. (2004). Dicionário de metodologia científica: um guia para a produção do conhecimento científico. São Paulo: Atlas.

Bosi, E. (1998). Cultura popular e cultura operária. Leituras operárias. In P. S. Oliveira (Org.), Metodologia das Ciências Humanas (pp. 199-219). São Paulo: Hucitec/Unesp.

Brandão, C. R. (1999). Participar-pesquisar. In C. R. Brandão (Org.), Repensando a pesquisa participante (pp. 7-14). São Paulo: Brasiliense.

Calegare, M. G. A. (2010a). Contribuições da Psicologia Social ao estudo de uma comunidade ribeirinha no Alto 
Solimões: redes comunitárias e identidades coletivas. Tese de Doutorado, Instituto de Psicologia, Universidade de São Paulo, São Paulo.

Calegare, M. G. A. (2010b). Abordagens em Psicologia Social e seu ensino. Revista Transformações em Psicologia, 3(2), $1-16$.

Campos, R. H. F. (1996). Introdução: a psicologia social comunitária. In R. H. F. Campos (Org.), Psicologia Social Comunitária: da solidariedade à autonomia $\left(11^{\mathrm{a}} \mathrm{ed} ., \mathrm{pp}\right.$. 9-15). Petrópolis, RJ: Vozes.

Chaves, M. P. S. R. (2001). Uma experiência de Pesquisa-ação para gestão de tecnologias apropriadas na Amazônia: o estudo de caso do assentamento de Reforma Agrária Iporá. Tese de Doutorado, Universidade Estadual de Campinas, Campinas, SP.

Diegues, A. C. S. (2004). A pesca construindo sociedades: leituras em antropologia marítima e pesqueira. São Paulo: NUPAUB/USP.

Fazenda, I. C. A. (2007). Interdisciplinaridade: história, teoria e pesquisa $\left(14^{\mathrm{a}} \mathrm{ed}.\right)$. Campinas, SP: Papirus.

Freitas, M. F. Q. (1999). Grupos, entrevistas coletivas e produção de conhecimento popular em trabalhos da psicologia comunitária. PSYKHE, 8(1), 189-194.

Freitas, M. F. Q. (2001). Psicologia social comunitária latinoamericana: algumas aproximações e intersecções com a psicologia política. Revista de Psicologia Politica, 1(2), 71 92.

Guareschi, P. A. (1996). Relações comunitárias relações de dominação. In R. H. F. Campos (Org.), Psicologia Social Comunitária: da solidariedade à autonomia $\left(11^{\mathrm{a}}\right.$ ed., pp. 81 99). Petrópolis, RJ: Vozes.

Günther, H., Elali, G. A., \& Pinheiro, J. Q. (2011). Multimétodos. In S. Cavalcante \& G. A. Elali (Orgs.), Temas básicos em Psicologia Ambiental (pp. 239-349). Petrópolis, RJ: Vozes.

Japiassu, H.F. (1975). O mito da neutralidade científica. Rio de Janeiro: Imago.

Lervolino, S. A. \& Pelicioni, M. C. F. (2001). A utilização do grupo focal como metodologia qualitativa na promoção da Saúde. Revista da Escola de Enfermagem USP, 35(2), 115121.

Martín-Baró, I. (1998). Psicología de la liberación. Madrid: Trotta.

Minayo, M. C. S. (2005). Conceito de avaliação por triangulação de métodos. In M. C. S. Minayo, S. G. Assis, \& E. R. Souza (Orgs.), Avaliação por triangulação de métodos: abordagem de programas sociais (pp. 19-51). Rio de Janeiro: Fiocruz.

Minayo, M. C. S. (Org.). (2007). Pesquisa social: teoria, método e criatividade (26 a ed.). Petrópolis, RJ: Vozes.

Montero, M. (2009). ¿Para qué Psicología Política? Revista Psicologia Política, 9(18), 199-213.

Oliveira, M. F. G. (2008). A organização política dos pescadores em uma comunidade ribeirinha no município de Tabatinga/ $A M$. Dissertação de Mestrado, Universidade Federal do Amazonas, Manaus.

Oliveira, R. C. (2006). O trabalho do Antropólogo ( $2^{\mathrm{a}}$ ed.). Brasília: Paralelo 15; São Paulo: Editora Unesp.

Prado, M. A. M. (2001). Psicologia Política e ação coletiva: notas e reflexes acerca da compreensão do processo de formação identitária do 'nós'. Revista Psicologia Política, 1(1), 149-172.

Schmidt, M. L. S. (2006). Pesquisa Participante: alteridade e comunidades interpretativas. Revista Psicologia USP, 17(2), 11-39.
Silva, E. C. L. (2008). A dinâmica das relações comunitárias na Amazônia: estudo de caso das formas de ajuda mútua praticadas na comunidade ribeirinha de Tauaru no município de Tabatinga-AM. Dissertação de Mestrado, Universidade Federal do Amazonas, Manaus.

Simonian, L. T. L. (2007). Uma relação que se amplia: fotografia e ciência sobre e na Amazônia. In C. Kahwage \& S. Ruggeri (Orgs.), Imagem e pesquisa na Amazônia: ferramentas de compreensão da realidade (pp. 15-52). Belém: Alves Gráfica e Editora.

Sommer, R. (2003). Em direção a uma Psicologia do comportamento natural. Brasília: LPA.

Thiollent, M. (1988). Metodologia da pesquisa-ação (4a ed.). São Paulo: Cortez.

Wallace, A. R. (1853). A narrative of travels on the Amazon and Rio Negro, with an account of the native tribes, and observations on the climate, geology, and natural history of the Amazon Valley. London: Reeve.

Recebido em: 08/03/2012

Aceite em: 14/04/2013

Marcelo Gustavo Aguilar Calegare é graduado em Psicologia pela Universidade de São Paulo (2002), mestrado (2005) e doutorado (2010) em Psicologia Social pela USP. Bolsista de Desenvolvimento Científico Regional (DCR) da FAPEAM / CNPq, no Laboratório de Psicologia e Educação Ambiental (LAPSEA) do Instituto Nacional de Pesquisas da Amazônia (INPA). Colaborador no Programa de Pós-Graduação em Psicologia da Universidade Federal do Amazonas (UFAM). Endereço: INPA - Lapsea - Sala 02. Av. André Araújo, 2.936. Petrópolis. Manaus/AM, Brasil. CEP 69067-375 E-mail: mgacalegare@gmail.com

Maria Inês Gasparetto Higuchi é Bolsista de Produtividade em Pesquisa do CNPq - Nível 2. Possui graduação em Psicologia pela Pontifícia Universidade Católica do Paraná (1979), mestrado em Ecologia Humana - Michigan State University (1986) e doutorado em Antropologia Social Brunel University (1999). Pesquisadora titular do Instituto Nacional de Pesquisas da Amazônia (INPA), coordena o Laboratório de Psicologia e Educação Ambiental (LAPSEA). Docente permanente no Programa de PósGraduação em Psicologia e no Programa de Pós-Graduação em Ciências do Ambiente e Sustentabilidade na Amazônia, ambos da Universidade Federal do Amazonas (UFAM). E-mail: mines@inpa.gov.br

Sylvia Souza Forsberg é graduada em Psicologia pelo Centro Universitário Luterano de Manaus (2004), especialista em Saúde Ambiental pela FIOCRUZ-Manaus (2010), mestre em Ciências do Ambiente e Sustentabilidade na Amazônia pela UFAM (2012). E-mail: sylviaforsberg@gmail.com

\section{Como citar:}

Calegare, M. G. A., Higuchi, M. I. G., \& Forsberg, S. S. (2013). Desafios metodológicos ao estudo de comunidades ribeirinhas amazônicas. Psicologia \& Sociedade, 25(3), 571-580. 